\title{
ENHANCED TRAFFIC CONTROL DEVICES AT PASSIVE HIGHWAY-RAILROAD GRADE CROSSINGS
}

\author{
by \\ David A. Noyce \\ Graduate Research Assistant \\ Texas Transportation Institute \\ Texas A\&M University System \\ College Station, TX 77843-3135 \\ Telephone: 409-845-1907 \\ Fax: 409-845-6481 \\ Email: dnoyce@ttiadmin.tamu.edu \\ and \\ Daniel B. Fambro \\ Associate Professor \\ Department of Civil Engineering \\ Texas A\&M University \\ College Station, TX 77843-3135 \\ Telephone: 409-845-1717 \\ Fax: 409-845-6481 \\ Email: d-fambro@tamu.edu
}

A Paper Prepared for the 78th Annual Meeting of the Transportation Research Board, Washington, D.C.

January 1998

Length of Paper:

4,971 words, 6 figures +4 tables @ 250 words each

7,471 equivalent words 


\section{INTRODUCTION}

According to a 1995 Federal Railroad Administration report, there are approximately 166,000 public highway-railroad grade crossing in the United States (1). Nearly 66,000 of these highwayrailroad grade crossings are classified as active crossings. Active crossings contain devices that warn drivers of the approach or presence of a train (2). The remaining 100,000 highway-railroad grade crossings are classified as passive crossings. Passive crossings lack train-activated warning devices and employ signs and pavement markings to identify the location of the crossing and to direct the attention of the motorist, bicyclist, or pedestrian (2). Passive devices provide static messages; the message conveyed by the advanced warning signs and markings remain constant regardless of the presence or absence of a train. Both passive and active crossings use the same advance warning signs and markings to alert drivers that a railroad grade crossing is nearby. In 1994, over 2,000 crashes occurred at public passive highway-railroad grade crossing resulting in 239 fatalities (1). The high number of crashes and fatalities at passive crossings provide evidence of a safety problem.

Driver error is frequently cited as a factor in highway-railroad grade crossing crashes; however, engineering and human factors issues often contribute to the crash (3). Driver error may result from failure to perceive that a train is in hazardous proximity to the grade crossing. Alternatively, the driver may detect the train but erroneously decide that adequate time is available to clear the crossing. Explanations for the driver's failure to detect the train or faulty decision-making process are many; however, it has been suggested that a leading cause of poor decisions is violation of driver expectancy.

Another possible source of confusion to drivers encountering highway-railroad grade crossings is the current system of visual communication. The advance warning and railroad crossbuck signs do not differentiate between active and passive crossings, thereby complicating the drivers decisionmaking task. Methods for improving the communication between railroad advanced warning signs and the driver are needed to reduce driver confusion and improve the overall safety at highwayrailroad grade crossings.

\section{OBJECTIVE}

The objective of this study was to develop, test, and evaluate an improved method for communicating with drivers at passive highway-railroad grade crossings. Specifically, this research was formulated to evaluate the effectiveness of a vehicle-activated strobe and supplemental sign as enhancements to the railroad advanced warning sign at passive highway-railroad grade crossings. To be effective, the enhanced sign system should increase driver awareness of the highway-railroad grade crossing and result in more cautious behavior. At the same time, drivers should understand the meaning of the enhanced sign system, and the enhancements should not result in unsafe driver behavior on the approach to the highway-railroad grade crossing.

\section{BACKGROUND}

The Texas Transportation Institute recently completed a focus group and closed-course driving study to determine driver response to several enhancements to the railroad advance warning sign (4). 
Three alternatives were explored including an increase in sign reflectorization through improved sheeting, the addition of a continuously flashing yellow beacon, and the addition of a vehicleactivated strobe light. The flashing beacon and vehicle-activated strobe light were intended for use at passive highway-railroad grade crossings with the purpose of attracting drivers' attention and directing it to the railroad advanced warning sign. Focus group comments concerning both flashing light alternatives were generally positive and no adverse driver behavior was observed when drivers encountered either alternative in a closed-course driving study. Both the continuously flashing beacon and the vehicle-activated strobe light were identified as effective methods of increasing driver awareness of the railroad warning sign; however, the uniqueness of the vehicle-activated strobe light led participants to conclude that the strobe light may be more effective at attracting drivers' attention. Given these results, a field study of the vehicle-activated strobe light at a passive highway-railroad grade crossing was recommended.

One of the concerns raised in the focus group study was how drivers would interpret the meaning of flashing yellow lights at passive highway-railroad grade crossings. Some focus group participants indicated that they assumed the flashing light meant a train was at the crossing. This problem was greater with the continuously flashing beacon than with the vehicle-activated strobe light (4). A potential safety problem was created with this interpretation since the flashing light was designed to attract drivers' attention rather than to indicate the presence of a train at the crossing.

To overcome this problem, the research team and the Texas Department of Transportation developed a "LOOK FOR TRAIN AT CROSSING" supplemental sign to be installed directly below the railroad advanced warning sign (5). This sign provided the driver with a written message consistent with the desired action at the crossing and minimized the potential of a driver misunderstanding the meaning of the flashing strobe light. The sign contained 10-centimeter letters, using a 122-centimeter (48-inch) sign width. This letter height was based on a ratio of legibility distance to letter height of 7:1 assuming 20/20 Snellen vision. The design and sizing requirements for the supplemental sign are presented in Figure 1.

The final enhanced sign system is depicted in Figure 2. The full-sized strobe light chosen flashed at one-million candle power and 90 flashes-per-minute (fpm), well below the 600 to 1,200 fpm that can trigger seizures in drivers with epilepsy (6). A shield was placed in back of the strobe light limiting the visibility of the flash to only approaching traffic. A loop detector was used to provide vehicle activation of the strobe light. Power for the loop detector and strobe light system was provided by a solar charged 12-volt battery.

To assure that the strobe light was operating for a sufficient period of time before the vehicle was in visual range of the warning signs, the loop detectors were placed approximately 170 meters upstream of the strobe light location. A distance of 170 meters was selected using an average perception-reaction time and estimated sign legibility distance. As a vehicle passed over the loop detector, the strobe light was activated and flashed for approximately eight seconds. Eight seconds provided sufficient time for the driver to observe the strobe light, the railroad advance warning sign, and the supplemental sign. Since the purpose of the vehicle-activated strobe light was only to attract the attention of drivers, the location of the vehicle in relation to the enhancement sign system when the strobe light stopped flashing was not considered significant. 


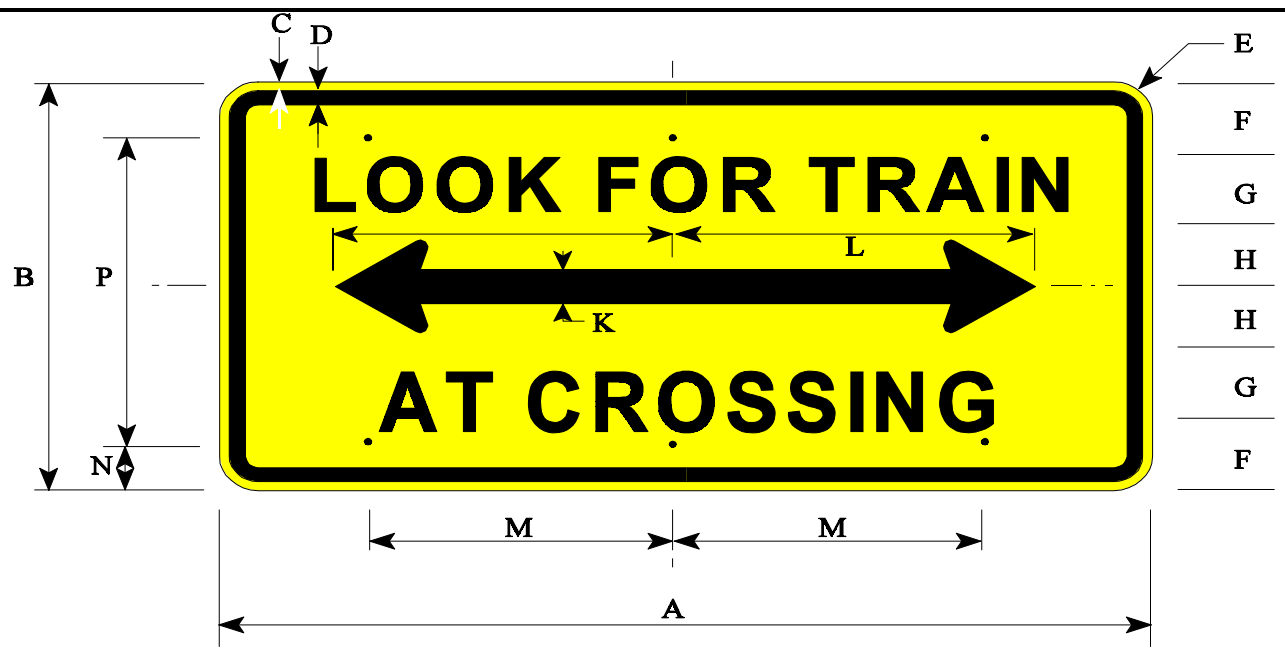

COLORS: Border, Legend \& Symbol - BLACK; Background - YELLOW (Reflectorized)

\section{Dimensions (Centimeters)}

\begin{tabular}{c|cccccccccccccc} 
Sign & A & B & C & D & E & F & G & H & J & K & L & M & N & P \\
\hline Special & 122 & 61 & 1 & 1.5 & 4 & 10 & $10 D$ & 10 & 13 & 5 & 46 & 40 & 8 & 51 \\
\hline
\end{tabular}

FIGURE 1 Supplemental Sign Design.

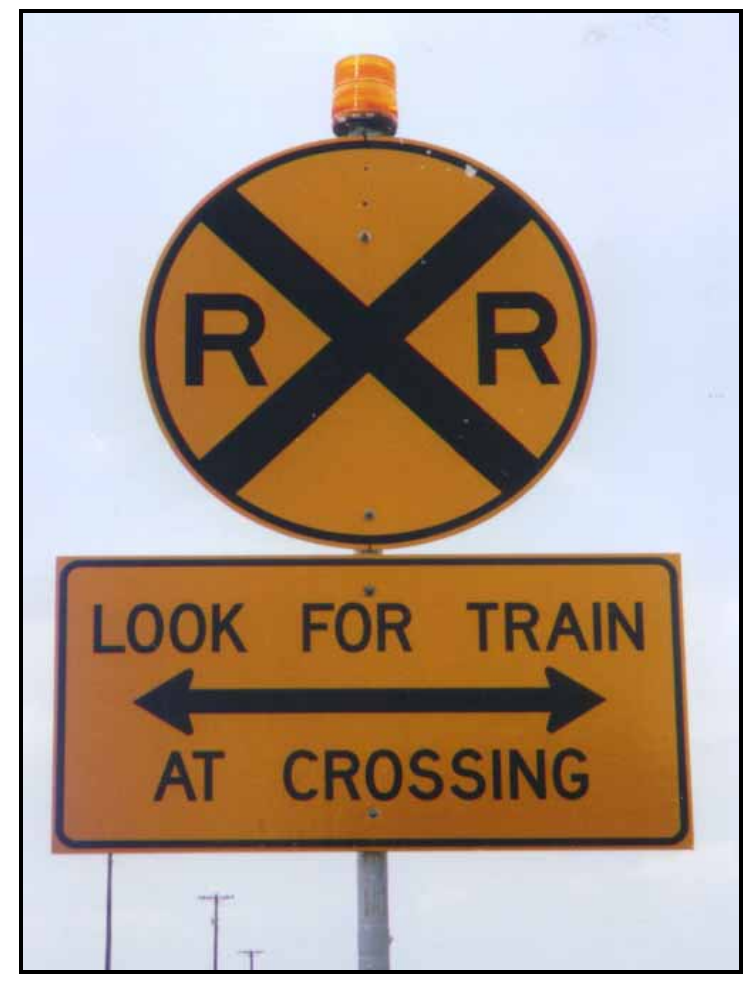

Figure 2 Enhanced Sign System. 


\section{STUDY METHOD}

The most effective way to determine if the enhanced sign system improved safety at passive highway-railroad grade crossings was to evaluate the crash rates at the crossing before and after installation. Since crash rates were not a viable measure for short term evaluation, three surrogate study methods were developed. First, a spot speed study was designed using a before and after methodology. Although railroad warning signs do not require drivers to reduce speed unless a train is present, the comparison of before and after speed profiles provided a means of determining if the objective of a more cautious approach to the highway-railroad crossing was achieved. The authors hypothesized that an effective sign enhancement would result in a speed reduction on the approach near the location of the enhanced sign system with little speed differential near the crossing. Second, a driver survey was developed and designed to evaluate the conspicuity (detection) of the flashing strobe light and supplemental sign. The survey was also used to determine drivers' comprehension of the enhanced sign system. Third, a driver observation study was developed to observe drivers' reaction to the strobe light.

A passive highway-railroad grade crossing on Blackland Road near Temple, Texas was selected as the study site. The railroad crossing on Blackland Road was slated for upgrading to an active crossing in June of 1997. Blackland Road was a rural cross-section roadway with average daily traffic volumes of 650 vehicles-per-day (vpd) and up to 15 daily train crossings. The Blackland Road study site contained two short-radius horizontal curves forming a reverse or S-curve roadway alignment approximately 50 meters west of the crossing and a crest vertical curve approximately 400 meters east of the crossing. The vertical curve limited the visibility of the crossing for eastbound drivers preventing drivers from observing the crossing until reaching the crest of the curve. None of the geometric features on the approach roadway were considered detrimental to the selection of Blackland Road as a study site.

A United States Department of Agriculture (USDA) facility was located in the northeast quadrant of the approach to the railroad crossing resulting in two driveway entrances and three field entrances within 375 meters of the crossing. The remaining three quadrants were open agricultural fields. Figure 3 presents a schematic drawing of the site.

\section{SPEED STUDY}

The before speed study was undertaken prior to any changes to the existing signs and traffic control on Blackland Road. Vehicle speeds were obtained during an eight-week period in January and February of 1997 by traffic classifiers placed 10, 50, 100, 150, 200, and 400 meters from the highway-railroad crossing. The classifier placed 400 meters from the crossing was used as a control location since it was outside the influence area of the flashing strobe light and beyond the visual range of the supplemental sign. Classifiers remained at each location for up to one week and collected data during all time periods. The field layout is shown in Figure 4.

The enhanced sign system was installed approximately four-weeks after the before speed study was completed. Supplemental sign installation took place approximately four-weeks prior to the commencement of the after speed data collection. The vehicle-activated strobe light was operated 


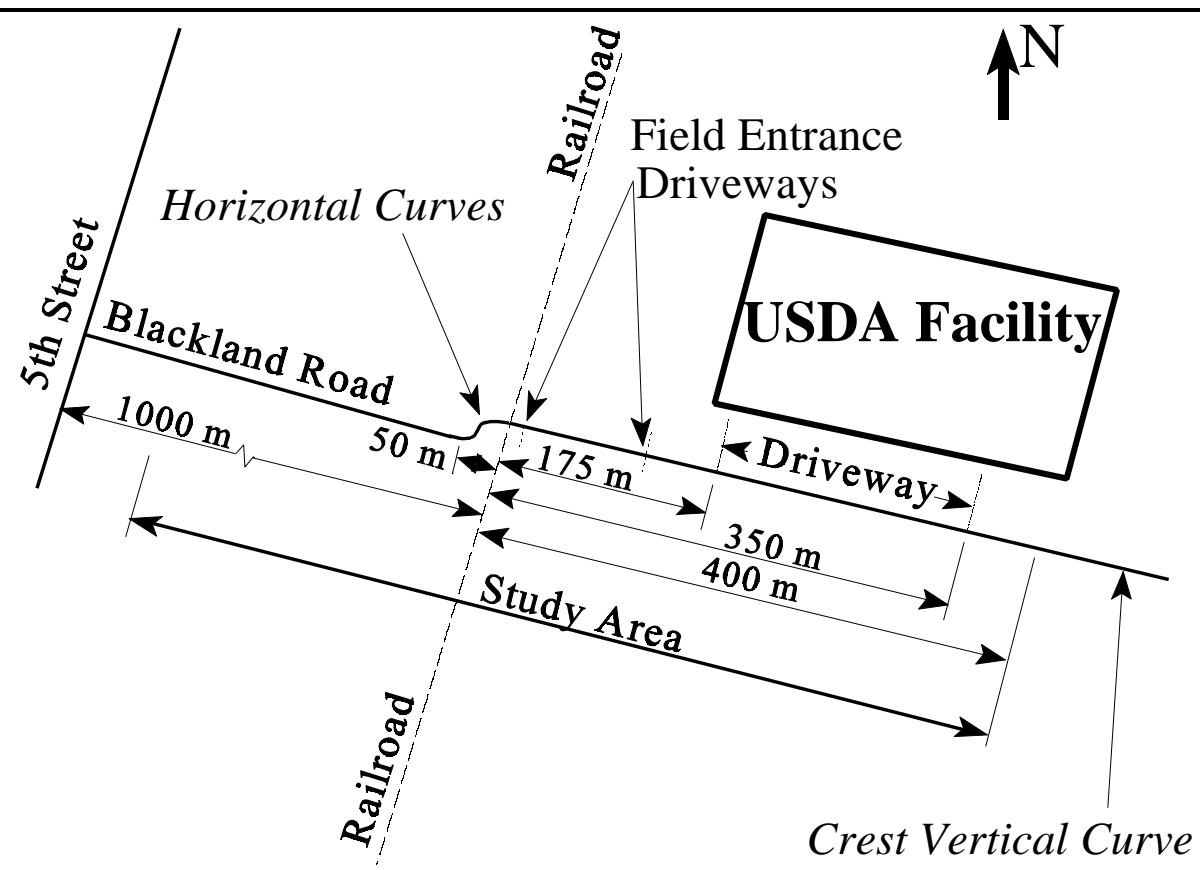

Figure 3 Blackland Road Study Site.

for a two-week period prior to the after study. This time was minimized since most drivers used Blackland Road on a daily basis.

The after speed study was conducted over a four-week period in May of 1997 using the same study methodology as the before speed study, including the same data collection equipment and locations. Tables 1 and 2 present the before and after speed results.

\section{Speed Study Results}

Figures 5 and 6 present the before and after average speeds on both the west and east approach to the railroad crossing. Figure 5 shows the average speeds for all of the data collected (day and night) while Figure 6 shows only average speeds obtained during night driving conditions (7 PM to 7 AM). Average speed data obtained in the after speed study at the 10- and 50-meter locations on the west approach were not available due to construction activities at the railroad crossing. Additional construction activities, including the installation of an active grade crossing, eliminated the opportunity to repeat the speed measurements under similar conditions.

Average day and night speeds in the after speed study on the west approach were somewhat lower at the 400-meter location and near the location of the enhanced sign system. Average speeds were approximately the same at the 200-meter location. Average speed on the east approach was slightly higher at the 400-meter location. Speeds were lower near the location of the enhanced sign system and approximately the same at locations near the crossing. 


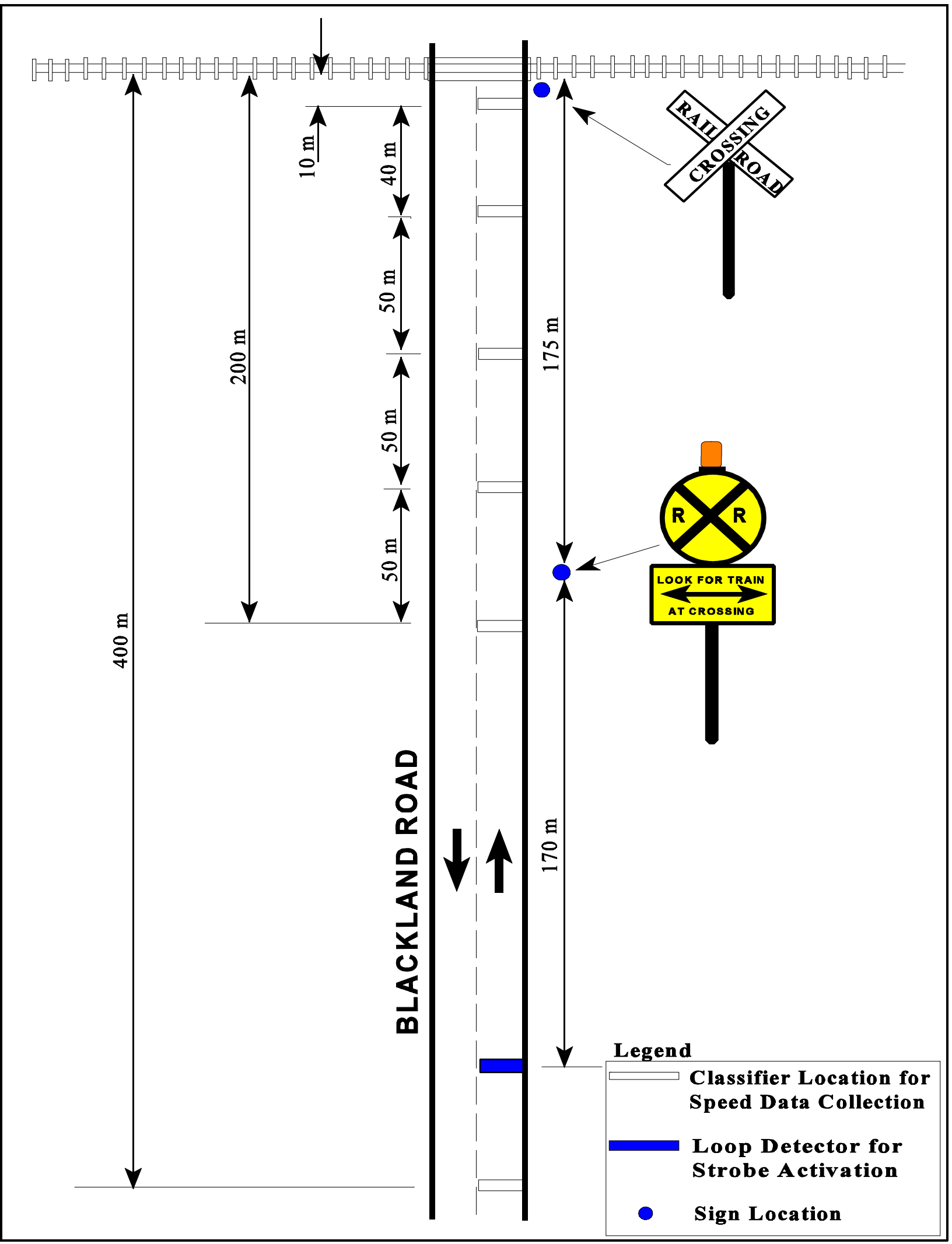

FIGURE 4 Field Layout for Data Collection. 
Table 1 Average Speed Results for the Before Study (Day and Night Conditions)

\begin{tabular}{|c|c|c|c|c|c|c|c|c|}
\hline \multirow{2}{*}{\multicolumn{2}{|c|}{$\begin{array}{l}\text { Distance from Crossing } \\
\text { (meters) }\end{array}$}} & \multirow{2}{*}{$\begin{array}{l}\text { Number of } \\
\text { Observations }\end{array}$} & \multicolumn{6}{|c|}{ Speeds (mph) } \\
\hline & & & Average & Std. Dev. & Min. & Max. & 15th \%ile & $85^{\text {th }} \%$ ile \\
\hline \multirow{6}{*}{$\begin{array}{c}\text { West } \\
\text { Approach }\end{array}$} & 400 & 2556 & 38.4 & 6.9 & 11 & 70 & 31.3 & 45.6 \\
\hline & 200 & 2093 & 35.2 & 6.8 & 5 & 70 & 28.6 & 42.2 \\
\hline & 150 & 2254 & 34.6 & 6.1 & 5 & 63 & 28.6 & 40.9 \\
\hline & 100 & 2252 & 32.0 & 5.7 & 5 & 49 & 26.5 & 37.5 \\
\hline & 50 & 2580 & 29.0 & 5.1 & 5 & 48 & 24.5 & 34.0 \\
\hline & 10 & 6283 & 18.2 & 4.6 & 3 & 40 & 13.6 & 22.5 \\
\hline \multirow{6}{*}{$\begin{array}{c}\text { East } \\
\text { Approach }\end{array}$} & 400 & 2058 & 41.2 & 9.0 & 10 & 77 & 30.6 & 49.7 \\
\hline & 200 & 1994 & 39.3 & 8.5 & 10 & 70 & 31.3 & 47.7 \\
\hline & 150 & 3145 & 37.6 & 9.3 & 4 & 85 & 29.3 & 46.3 \\
\hline & 100 & 3262 & 35.6 & 7.6 & 3 & 70 & 27.9 & 43.6 \\
\hline & 50 & 1364 & 30.8 & 5.4 & 10 & 51 & 25.9 & 36.1 \\
\hline & 10 & 1355 & 18.9 & 4.8 & 4 & 42 & 14.3 & 23.1 \\
\hline
\end{tabular}

Table 2 Average Speed Results for the After Study (Day and Night Conditions)

\begin{tabular}{|c|c|c|c|c|c|c|c|c|}
\hline \multirow{2}{*}{\multicolumn{2}{|c|}{$\begin{array}{c}\text { Distance from Crossing } \\
\text { (meters) }\end{array}$}} & \multirow{2}{*}{$\begin{array}{l}\text { Number of } \\
\text { Observations }\end{array}$} & \multicolumn{6}{|c|}{ Speeds (mph) } \\
\hline & & & Average & Std. Dev. & Min. & Max. & $15^{\text {th }} \%$ ile & $85^{\text {th }} \%$ ile \\
\hline \multirow{6}{*}{$\begin{array}{c}\text { West } \\
\text { Approach }\end{array}$} & 400 & 931 & 36.7 & 7.4 & 15 & 70 & 29.3 & 44.3 \\
\hline & 200 & 845 & 35.4 & 6.5 & 15 & 70 & 29.3 & 42.2 \\
\hline & 150 & 946 & 32.9 & 6.2 & 6 & 64 & 26.5 & 39.5 \\
\hline & 100 & 461 & 29.8 & 5.4 & 12 & 46 & 24.5 & 35.4 \\
\hline & 50 & 325 & 28.8 & 5.2 & 7 & 50 & 23.8 & 33.4 \\
\hline & 10 & 135 & 21.2 & 4.1 & 12 & 38 & 17.7 & 25.2 \\
\hline \multirow{6}{*}{$\begin{array}{c}\text { East } \\
\text { Approach }\end{array}$} & 400 & 1505 & 42.7 & 8.3 & 6 & 72 & 34.0 & 51.1 \\
\hline & 200 & 630 & 37.8 & 8.8 & 10 & 66 & 28.6 & 46.3 \\
\hline & 150 & 666 & 35.4 & 9.8 & 3 & 65 & 25.9 & 45.0 \\
\hline & 100 & 1982 & 35.8 & 7.5 & 3 & 59 & 27.9 & 43.6 \\
\hline & 50 & 1997 & 30.4 & 5.6 & 7 & 55 & 25.2 & 36.1 \\
\hline & 10 & 1728 & 19.1 & 4.8 & 4 & 40 & 14.3 & 23.8 \\
\hline
\end{tabular}




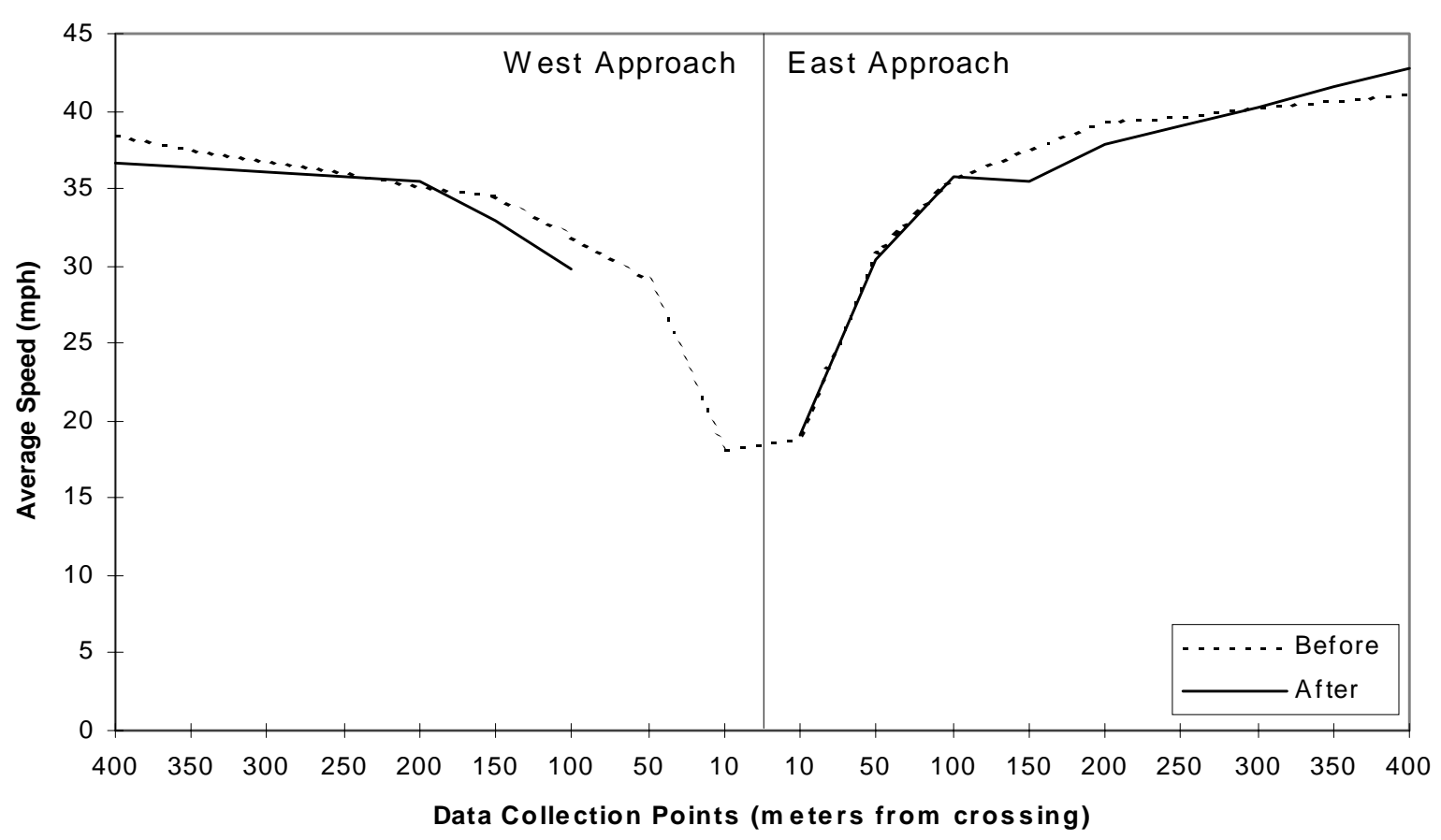

FIGURE 5 Average Speeds on East and West Approach with All Data Points.

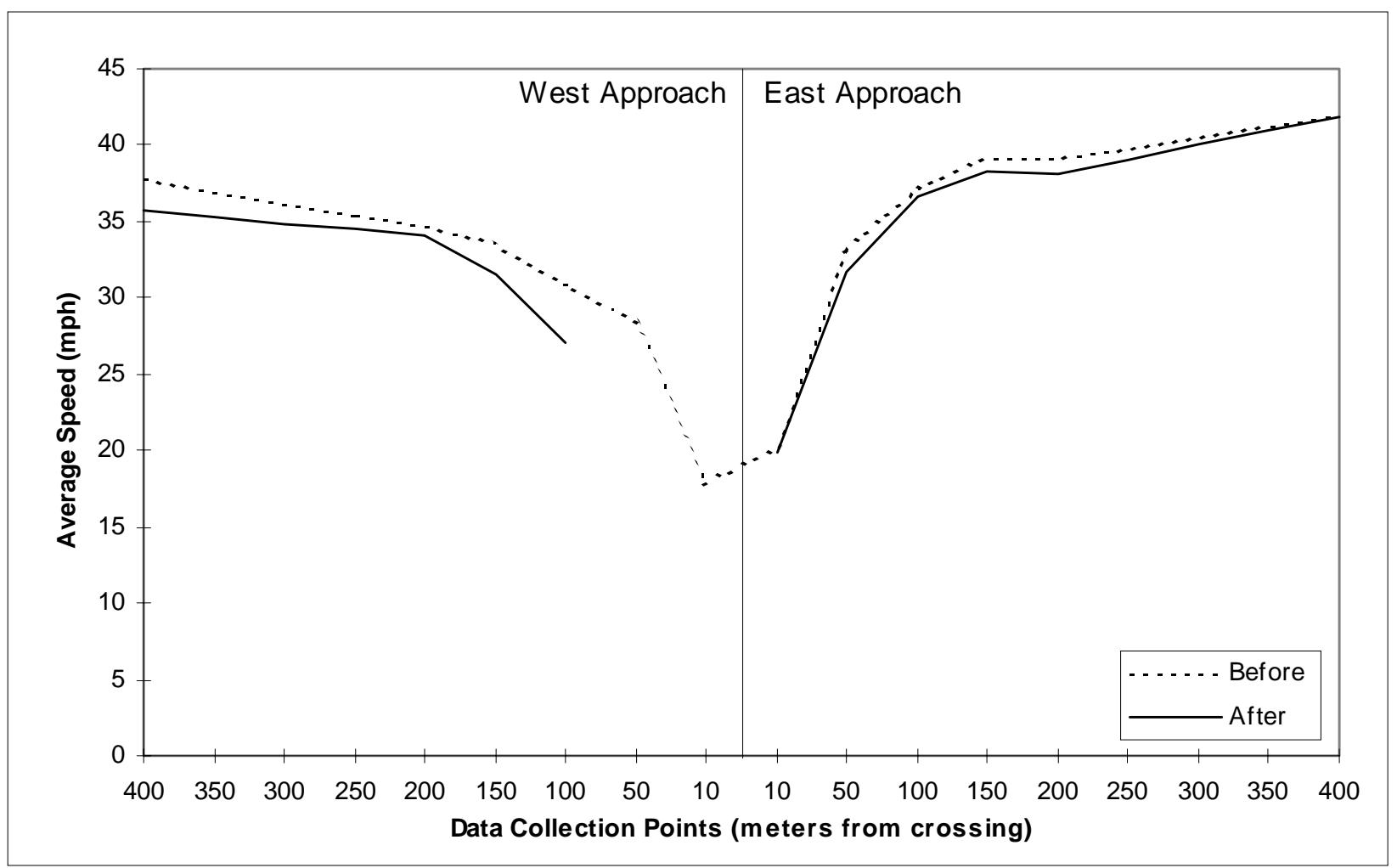

FIGURE 6 Average Speeds on East and West Approach with only Night Data Points. 
Average night speeds on the west approach were lower in the after study at all locations. Average night speeds on the east approach were nearly identical at the 400-meter location and slightly lower at all of the other data collection locations.

A statistical comparison of the before and after speeds at each location was completed to determine whether the speed changes were significant. The results are presented in Tables 3 and 4. Significant decreases in average speed were found at the 100-, 150-, and 400-meter locations on the west approach. A significant increase in average speed was found at the 400-meter location on the east approach. This increase in average speed at the 400-meter location was attributed roadway pavement improvements upstream of the study site. Significant decreases in average speed was found at the 50-, 150-, and 200-meter locations on the east approach. The reduction in average speed in the after study was further emphasized by the increase in average speed at the 400-meter location.

A statistical comparison considering only night driving speed results found significant speed reductions on the west approach at the 100-, 150- and 400-meter locations. A decrease in average speed was also observed at the 200-meter location but not at a significant level. Only the 50-meter location on the east approach showed a significant decrease in average speed. All other locations on the east approach showed decreases in average speed; however, not at a statistically significant level.

The results of the before and after speed study provides evidence that the addition of the enhanced sign system led to lower vehicle approach speeds. The significant increase in average speed on the east approach at the 400-meter location, followed by a significant decrease in average speed at the 50-, 150- and 200-meter locations, provides some indication that the enhanced sign system caused drivers to reduce speed as they approach the railroad crossing. A reduction in average speeds was observed at all east approach study locations during night conditions.

Significant reductions in average speed were found on the west approach at the 100-, 150- and 400-meter locations during both day and night driving conditions. Although the results at the 10and 50-meter locations in the after speed study were not available, the observation of vehicles and the results upstream of these study locations suggested that speed reductions would have been observed throughout the west approach.

The study locations located 100-meter from the crossing on each approach provided the last speed measure before an approaching vehicle entered the nonrecovery zone. This zone is defined as the area of the approach where the amount of roadway is insufficient to avoid a collision if the stop/go decision has not already been made (7). The beginning of the nonrecovery zone coincides with the stopping sight distance point or the minimum visible distance required to sight an object in the roadway necessitating a stop and to safely stop the vehicle. Actual stopping sight distances vary with approach speed, reaction time, pavement friction, tire conditions, and deceleration rates, but can be considered to be between 50 and 100 meters given the prevailing conditions on Blackland Road.

Average speeds on the west approach at the 100-meter location decreased approximately 7 percent from $32.0 \mathrm{mph}$ in the before speed study to $29.8 \mathrm{mph}$ in the after speed study. Similarly, average night speeds decreased approximately 13 percent from $31.0 \mathrm{mph}$ in the before speed study 
TABLE 3 Comparison of Before and After Average Speed Values (Day and Night Conditions)

\begin{tabular}{|c|c|c|c|c|c|c|}
\hline \multirow{2}{*}{\multicolumn{2}{|c|}{$\begin{array}{c}\text { Distance from Crossing } \\
\text { (meters) }\end{array}$}} & \multicolumn{3}{|c|}{ Average Speed (mph) } & \multirow[b]{2}{*}{$p$-Value } & \multirow[b]{2}{*}{ Significan } \\
\hline & & Before & After & Difference & & \\
\hline \multirow{6}{*}{$\begin{array}{c}\text { West } \\
\text { Approach }\end{array}$} & 400 & 38.4 & 36.7 & 1.7 & .0001 & Yes \\
\hline & 200 & 35.2 & 35.4 & -0.2 & -.484 & No \\
\hline & 150 & 34.6 & 32.9 & 1.7 & .0001 & Yes \\
\hline & 100 & 32.0 & 29.8 & 2.2 & .0001 & Yes \\
\hline & $50 *$ & 29.0 & --- & --- & --- & --- \\
\hline & $10 *$ & 18.2 & --- & --- & --- & --- \\
\hline \multirow{6}{*}{$\begin{array}{c}\text { East } \\
\text { Approach }\end{array}$} & 400 & 41.2 & 42.7 & -1.5 & -.0001 & Yes \\
\hline & 200 & 39.3 & 37.8 & 1.5 & .0002 & Yes \\
\hline & 150 & 37.6 & 35.4 & 2.2 & .0001 & Yes \\
\hline & 100 & 35.6 & 35.8 & -0.2 & -.368 & No \\
\hline & 50 & 30.8 & 30.4 & 0.4 & .036 & Yes \\
\hline & 10 & 18.9 & 19.1 & -0.2 & -.271 & No \\
\hline
\end{tabular}

\section{TABLE 4 Comparison of Before and After Average Speed Values (Night Conditions)}

\begin{tabular}{|c|c|c|c|c|c|c|}
\hline \multirow{2}{*}{\multicolumn{2}{|c|}{$\begin{array}{c}\text { Distance from Crossing } \\
\text { (meters) }\end{array}$}} & \multicolumn{3}{|c|}{ Average Speed (mph) } & \multirow[b]{2}{*}{$p$-Value } & \multirow[b]{2}{*}{ Significant } \\
\hline & & Before & After & Difference & & \\
\hline \multirow{6}{*}{$\begin{array}{c}\text { West } \\
\text { Approach }\end{array}$} & 400 & 37.8 & 35.7 & 2.1 & .001 & Yes \\
\hline & 200 & 34.7 & 34.1 & 0.6 & .368 & No \\
\hline & 150 & 33.6 & 31.6 & 2.0 & .001 & Yes \\
\hline & 100 & 31.0 & 27.0 & 4.0 & .0001 & Yes \\
\hline & $50^{*}$ & 28.4 & --- & --- & --- & --- \\
\hline & $10^{*}$ & 17.8 & --- & --- & --- & --- \\
\hline \multirow{6}{*}{$\begin{array}{c}\text { East } \\
\text { Approach }\end{array}$} & 400 & 42.0 & 41.9 & 0.1 & .841 & No \\
\hline & 200 & 39.1 & 38.1 & 1.0 & .230 & No \\
\hline & 150 & 39.1 & 38.3 & 0.8 & .270 & No \\
\hline & 100 & 37.2 & 36.7 & 0.5 & .317 & No \\
\hline & 50 & 33.1 & 31.7 & 1.4 & .007 & Yes \\
\hline & 10 & 20.2 & 19.9 & 0.3 & .548 & No \\
\hline
\end{tabular}


to $27.0 \mathrm{mph}$ in the after speed study. Speed variances in both day and night conditions were also lower in the after speed study. Average speeds and speed variances on the east approach remained consistent in both the before and after conditions.

The findings on the west approach were consistent with the hypothesis and suggest that the enhanced sign system was effective in reducing vehicle speeds as drivers entered the nonrecovery zone. This reduction in average speeds also reduced stopping distance requirements which may have a positive effect on the safety of the crossing. The reasons why average speeds remained rather consistent on the east approach can probably be attributed to the existing geometric features of the roadway. The crest vertical curve on the east approach and the USDA driveway and field entrances may cause drivers to enter the study site at a comfortable speed, minimizing the need for significant speed reduction and minimizing the potential speed impact of the enhanced sign system. Also, eastbound drivers had ample time to reach their desired operating speed on Blackland Road minimizing the need for significant speed reductions on the railroad approach.

\section{DRIVER SURVEYS}

Westbound drivers were surveyed as they stopped at the $5^{\text {th }}$ Street intersection. The survey was conducted from 6:30 to 8:30 PM during the period of mesopic vision (dusk) conditions. Although it would be desirable to have survey data during scotopic vision (night) conditions, safety concerns prevented data collection during this time period. After stopping, drivers were first asked to recall the approach to the railroad they just crossed and whether they had noticed anything different or unique as compared with other similar crossings. If the driver answered yes, he or she was asked what it was that they had noticed. Drivers that mentioned the strobe light were asked how they reacted. Drivers that did not mention the strobe light were asked if they noticed a yellow flashing strobe light on the railroad warning sign. Drivers answering yes to this question were also asked how they reacted to it. Each driver was then asked what they thought the strobe light meant and if they felt a flashing strobe light would bother them during night driving conditions.

The second part of the survey focused on the supplemental sign. Drivers who did not mention the supplemental sign as part of the first question were told that there was an additional sign under the railroad warning sign. They were then asked if they recalled seeing this sign. Drivers that responded yes to this question were asked to recall what was on the sign. Drivers answering no were told what was written on the sign. Drivers were then asked what they thought the sign meant. Finally, a number of categorical items were recorded including how frequently they use Blackland Road, the age and gender of each driver, and the time of the survey.

\section{Survey Results}

A total of 33 valid surveys were obtained from 23 male and 10 female drivers. Eighty-two percent of the drivers indicated that they used Blackland Road frequently, consistent with the author's expectations. When asked if they noticed anything unique or different about the railroad crossing, 52 percent of the drivers indicated that they had. This response rate was a significant improvement over previous studies where only 20 percent of drivers were found to recall and use the railroad warning signs (8). Of the drivers who indicated that they had noticed something unique or different, 88 percent (15 of 17) identified the strobe light and 71 percent identified the 
supplemental sign. Twenty-one of the 33 drivers surveyed recalled observing the flashing strobe light, including six drivers who did not consider the flashing strobe light unique or different.

There appeared to be a distinct trend in the frequency of positive responses. Before 7:45 PM, 29 percent of the drivers indicated that they noticed something unique or uncommon while after 7:45 PM, 75 percent of the drivers reported noticing something unique about the crossing. Thirteen of the 21 positive responses to observing the strobe light were obtained after 7:45 PM. Although the reasons for this trend are not completely clear, it would appear that there was a relationship between the degree of darkness and the conspicuity of the strobe light.

The strobe light elicited two general responses, either the use of additional caution at the railroad crossing or no response at all. Nineteen drivers stated they used additional caution which included speed reduction (braking), reading the warning signs, looking for trains, or stopping at the crossing. The remaining 14 drivers did nothing, many because they did not observe or recall observing the flashing strobe light. Drivers were asked if they believed that a strobe light would bother them during night driving conditions. None of the drivers who responded indicated that a flashing strobe light would bother them when driving at night.

When drivers were asked what they thought the strobe light meant, eight of the respondents thought that the strobe light was a message to use extra caution at the crossing. Three of the drivers felt the strobe light meant to reduce speed and eight drivers felt that the sign meant pay attention, be careful, read the signs, or look for a train. The remaining responses were varied; however, none of the drivers related the flashing strobe light to the presence or lack of presence of a train at the crossing. All of the drivers surveyed related the implied meaning of the strobe light to the need for implementing some form of additional caution on the approach to the crossing.

The next section of the survey focused on the supplemental sign. Overall, 55 percent (18 of 33) of the drivers indicated that they observed the supplemental sign. Of the 18 drivers who observed the sign, five were able to correctly recall the sign wording, six derived similar wording, and seven were not able to recall the words. Prior to 7:45 PM, 47 percent recalled observing the sign, although only 18 percent recalled the wording on the sign. After 7:45 PM, 63 percent of the drivers surveyed reported seeing the sign and 50 percent recalled the wording on the sign. A number of drivers indicated that the supplemental sign caused them to drive with additional caution because they assumed that transportation officials would not have installed the supplemental sign if the crossing was not unsafe.

The survey results indicated that the flashing strobe light is more effective at gaining drivers attention during scotopic vision conditions than photopic or mesopic conditions. This result is not surprising since the flashing strobe light was difficult to detect in bright sunlight. Second, there appears to be a relationship between the frequency of roadway use and the observance of the warning signs. Drivers who used Blackland Road everyday were less likely to observe the flashing strobe light and supplemental sign than unfamiliar drivers. Third, 9 of the 11 drivers who recalled the wording of the supplemental sign chose to use additional caution at the railroad crossing. Finally, three of the five unfamiliar drivers surveyed stated that they observed the flashing strobe light, observed the supplemental sign, and were able to recall the wording of the sign. The strobe light was effective in attracting the attention of drivers who were unfamiliar with the railroad crossing. 


\section{DRIVER OBSERVATION STUDY}

The driver observation study was conducted during night driving conditions when the flashing strobe light had maximum contrast luminance. An observer was positioned approximately 180 meters upstream of the enhanced sign system near the loop detector location. The reaction of each vehicle was monitored starting at the point at which the vehicle activated the flashing strobe light and ending at the railway crossing. Driver reaction was considered to be anything visible to the observer including braking, weaving, swerving, and related vehicle maneuvers. Because this study was completed at night, drivers looking behavior and associated head movements at the approach to the railroad crossing could not be observed.

\section{Study Results}

Eighteen drivers were observed over a three-hour period, 12 of which exhibited no apparent reaction to the strobe light. No reaction was considered to be typical behavior; braking approximately 100 meters from the crossing and crossing the railroad at reduced speeds ( $<48 \mathrm{~km} / \mathrm{h}$ ).

Six drivers demonstrated changes in behavior due to the strobe light although their observed reactions were not considered severe. On the contrary, their reactions indicated that they were exercising additional caution on the approach to the crossing. Three of the drivers applied the vehicle's brakes in the vicinity of the warning sign and flashing strobe light and one driver switched on their hi-beam headlights, presumably to read the warning signs. One driver stopped at the crossing, another driver applied brakes the moment the strobe light was activated, and a driver crossed the railway line at a speed below $16 \mathrm{~km} / \mathrm{h}$ with hi-beam headlights. No adverse driver reaction to the strobe light was observed.

\section{SUMMARY}

The results of this research indicate that the enhanced sign system can be effective at reducing speeds and attracting drivers' attention on the approach to passive highway-railroad grade crossings. Average speeds on the approaches to the crossing were found to be lower after the installation of the enhanced sign system with the greatest speed reduction near its location on the approach.

Reduction in average speeds were found at all study locations during night driving conditions. A 13 percent reduction at the 100-meter study location on the west approach represented the largest speed reduction. It is difficult to predict how much of the speed reduction is directly attributable to the enhanced sign system; however, it is safe to conclude that the enhanced sign system had a positive contribution in producing speed reductions on each approach to the railroad crossing.

Drivers responded favorably to the addition of the enhanced sign system. The number of familiar and unfamiliar drivers who recalled observing the supplemental sign was encouraging, especially the number of drivers who were able to recite the exact wording of this unfamiliar sign. Further, the addition of the flashing strobe light and supplemental sign enhancements to the existing W10-1 sign indicated to some drivers that transportation officials considered this location to be an unsafe highway-railroad grade crossing. These same drivers indicated that they approached the railroad crossing with more caution than in the past. None of the drivers surveyed indicated that they inferred 
the meaning of the flashing strobe light to be correlated to the presence of a train at the crossing. Also, no adverse driver reactions were reported or observed at the onset of the flashing strobe light.

Just before complete darkness, the two drivers surveyed claimed that they did not observe the flashing strobe light but did see the supplemental sign. Since the purpose of the flashing strobe light is to attract drivers' attention to the warning $\operatorname{sign}(\mathrm{s})$, not to the strobe light itself, it appears that the enhanced sign system performed as desired in these two instances.

\section{CONCLUSIONS}

The conclusions to the research findings described above can be summarized as follows:

- The enhanced sign system appears to increase driver awareness of the passive highwayrailroad grade crossing;

- The enhanced sign system caused some drivers to approach the passive grade crossing with additional caution;

- Reductions in average speeds on both the east and west approach to the highway-railroad grade crossing were observed after the installation of the enhanced sign system;

- The strobe light was effective in directing drivers' attention to the railroad advanced warning (W10-1) and supplemental signs;

- The enhanced sign system did not cause any adverse driver behavior.

\section{RECOMMENDATIONS}

The vehicle-activated strobe light enhancement appears effective at improving the communication with drivers at passive highway-railroad grade crossings. Since these conclusions are based only on the results of one study site, additional research is required to validate the effectiveness of the enhanced sign system. The vehicle-activated strobe light and supplemental sign should be installed and evaluated at additional crossings, desirably, as an interim device between the selection of a passive crossing for improvement and the installation of the active crossing devices.

\section{ACKNOWLEDGMENTS}

The research reported herein was performed by Texas Transportation Institute (TTI) as part of a study entitled "Enhanced Traffic Control Devices and Railroad Operations for Highway-Railroad Grade Crossings," sponsored by the Texas Department of Transportation (TxDOT) in cooperation with the Federal Highway Administration. The authors wish to acknowledge the contributions of the TxDOT Technical Advisory Committee along with Andre Frieslaar and LuAnn Copeland of TTI. 


\section{REFERENCES}

1. Highway-Rail Crossing Accident/Incident and Inventory Bulletin. Report No. 17, Federal Railroad Administration, U.S. Department of Transportation, July 1995.

2. Manual on Uniform Traffic Control Devices. FHWA, U.S. Department of Transportation, Washington, D.C., 1988.

3. Berg, W. D., K. Knoblach, and W. Hueke. Causal Factors in Railroad-Highway Crossing Crashes. In Transportation Research Record 847, TRB, National Research Council, Washington, D.C., 1982, pp. 47-54.

4. Fambro, Daniel B., Lee Anne Shull, David A. Noyce, and K. M. A. Rahman. Enhanced Traffic Control Devices and Railroad Operations for Highway-Railroad Grade Crossing: Second Year Activities. Report 1469-2, Texas Transportation Institute, Texas A\&M University System, College Station, Texas, 1997.

5. Fambro, Daniel B., David A. Noyce, Andre H. Frieslaar and LuAnn D. Copeland. Enhanced Traffic Control Devices and Railroad Operations for Highway-Railroad Grade Crossing: Third Year Activities. Report 1469-3, Texas Transportation Institute, Texas A\&M University System, College Station, Texas, 1997.

6. The Epilepsy Foundation of America, Bethesda, MD, 1997, web site http://www.efa.org.

7. Tustin, B.H., H. Richards, H. McGee and R. Patterson. Railroad-Highway Grade Crossing Handbook. $2^{\text {nd }}$ Edition. Report FHWA-TS-86-215, FHWA, U.S. Department of Transportation, 1986.

8. Sanders, James H. Driver Performance in Countermeasure Development at Railroad-Highway Grade Crossings. In Transportation Research Record 562, TRB, National Research Council, Washington, D.C., 1976, pp. 28-37. 